\title{
Efeitos fiscais e macroeconômicos da emenda constitucional do teto dos gastos $\left(n^{\circ}\right.$ 95/2016) ${ }^{1}$
}

Fiscal and macroeconomic effects of the constitutional amendment to the spending ceiling (n 95/2016)

\author{
José Weligton Félix Gomes (1,2) \\ Ricardo A. de Castro Pereira (2,4) \\ Arley Rodrigues Bezerra ${ }^{(3)}$ \\ Francisco Germano Carvalho Lucio(2) \\ Francisco Assuero Monteiro Saraiva (2)
}

(1) Universidade Federal do Ceará (UFC/Sobral) (2) Universidade Federal do Ceará (CAEN/UFC)

(3) Universidade Federal Rural de Pernambuco

(4) Instituto de Pesquisa e Estratégia Econômica

do Ceará (IPECE)

\begin{abstract}
This paper investigates the effects of the Constitutional Amendment No. 95/2016 on fiscal management, economic growth, and families' welfare. It uses a dynamic general equilibrium model with heterogeneous agents. The model includes congestion in the government's offer of consumer services to households and public capital to firms. Considering the population growth, the freezing of public spending proposed by EC 95/2016 could bring a strong reduction in the level of services offered to families, especially in the poorest strata. Alternative policies that allow the variation of public investments accompanied by compensation for losses by the poorest would not only generate allocation efficiency gains and improvement in the redistribution of income, but also the reversal of bottlenecks and sustained economic growth. The product of the economy would grow $9.2 \%$, after 10 years of the EC 95/2016, driven by public investment.
\end{abstract}

\section{Keywords}

economic growth, Constitutional amendment 95/2016, fiscal management.

JEL Codes C68, E62, H30.

\section{Resumo}

Este artigo avalia os efeitos da Emenda Constitucional $n^{\circ}$ 95/2016 na gestão fiscal, no crescimento econômico e no bem-estar das famílias. Para tanto, utilizou-se um modelo de equilíbrio geral dinâmico com agentes heterogêneos. O modelo comporta a congestão na oferta, pelo governo, de serviços de consumo às famílias e de capital público às firmas. Na presença de crescimento populacional o congelamento dos gastos públicos, proposto pela EC 95/2016, poderá trazer forte redução no nivel de serviços ofertados às famílias, sobretudo na camada mais pobre da população. Políticas alternativas que permitam variar os investimentos públicos acompanhadas de compensações das perdas pelos mais pobres gerariam não somente ganhos de eficiência alocativa e melhoria na redistribuição de renda, mas também a reversão de gargalos e o crescimento econômico sustentado. O produto da economia cresceria $9,2 \%$, decorridos 10 anos da EC 95, alavancado pelos investimentos públicos.

\section{Palavras-chave}

crescimento econômico, EC 95/2016, gestão fiscal. Códigos JEL C68, E62, H30.

1 Este artigo recebeu Menção Honrosa no X Prêmio SOF de Monografias 2018. 


\section{Introdução}

O atual cenário macroeconômico brasileiro é caracterizado por um intenso debate a respeito da evolução da trajetória da dívida pública e, por conseguinte, da gestão fiscal dos gastos públicos. A trajetória explosiva da dívida tem demandado a busca por soluções que venham conter os déficits fiscais, ${ }^{2}$ iniciado em 2014, após um período de distanciamento do "tripé"3 da política macroeconômica em 2009. Para Giambiagi (2008), entre os anos de 1992 e 2008, os gastos primários do governo cresceram a uma taxa média anual de $6 \%$, aproximadamente o dobro da média de crescimento da economia. De acordo com o Tesouro Nacional (TN), entre 1998 e 2013 o país acumulou um superávit primário de 2,1\% do PIB, o maior valor anual desde o ano de 1997. Esse instrumento de gestão fiscal ajudou a controlar a evolução da dívida pública mesmo diante da elevação nos gastos supracitados.

Dados referentes às Contas Nacionais do Brasil mostram que a partir dos anos 2000 a Dívida Líquida do Setor Público como parcela do Produto Interno Bruto (DLSP/PIB) apresenta uma trajetória decrescente em resposta aos significativos resultados primários e ao crescimento do produto. Segundo dados do Banco Central (Bacen), os superávits primários contribuíram para a redução média dessa relação em 2,7 pontos percentuais (p.p.) entre 2007 e 2012, enquanto o efeito crescimento do PIB contribuiu para a redução desse indicador em média em 4,4 p.p. no mesmo período.

Vale ressaltar, contudo, que esses mecanismos de gestão fiscal, mais especificamente de contenção da relação DLSP/PIB, perderam força a partir de 2011. Os superávits primários reduziram-se gradativamente de 2,3\% do PIB em 2008 para 1,4\% em 2013, tornando-se deficitário em 2014 e atingindo um déficit primário de $2,5 \%$ do PIB em 2016. Essa mudança no cenário fiscal foi ocasionada tanto pela trajetória crescente das despesas frente às receitas, com destaque para as despesas com a previdência social que aumentaram 0,97 pontos percentuais do PIB no período de 2002 a 2015 (Brasil, 2016a), quanto pela redução no nível de receitas.

\footnotetext{
2 O resultado fiscal é a diferença entre a arrecadação e os gastos do governo.

3 O tripé da política macroeconômica é formado pelo sistema de metas de inflação, pelo regime de câmbio flutuante e pela responsabilidade fiscal através de metas de superávit primário. Teve início no Brasil em 1999 e a partir de então passou a exercer papel fundamental como mecanismo de coordenação das demais políticas (Gerardo, 2010).
} 
Segundo Abreu e Lima (2018), a manutenção de políticas anticíclicas com aumento de despesas e isenções tributárias após a crise de 2008 bem como o fim do boom das commodities no mercado internacional são fatores que contribuíram para o cenário fiscal descrito. Adicionalmente, Souza Júnior e Santos (2017) apontam que entre 2001 e 2014 o Brasil apresentou alta expressiva na Dívida Bruta do Governo Geral (DBGG), tendo contribuído para isso um crescente déficit primário, queda no PIB, aumento do custo médio da dívida, continuidade das desonerações fiscais e aumento dos gastos.

Visando conter o crescimento acelerado dos gastos do governo o congresso instituiu o novo regime fiscal via aprovação da Emenda Constitucional (EC) No 95/2016 (Brasil, 2016b). Vale salientar que essa política é, de certo modo, limitada devido à rigidez na estrutura do gasto público brasileiro estabelecido pela Constituição Federal de 1988, tal como destacado por Santana et al. (2012). Dados do Tesouro Nacional mostram que essas despesas obrigatórias compunham aproximadamente $90 \%$ da despesa primária do governo central no ano de 2016. Contudo, nem toda despesa primária está sujeita ao limite imposto pelo Novo Regime Fiscal (NRF).

Nota-se, portanto, a importância do controle das contas públicas na promoção da estabilidade fiscal e no crescimento da economia. Contudo, Ball et al. (2013) e Bova et al. (2018) ${ }^{5}$ encontram resultados como aumento da desigualdade, redução de salários e aumento do desemprego advindos de políticas de austeridades em países da OCDE e na zona do euro, respectivamente. No entanto, Anderson et al. (2014) e Camuri et al. (2015) sugerem que não é possível generalizar empiricamente a relação entre crescimento econômico e redução do endividamento público. Os resultados empíricos adversos encontrados na literatura refletem a ausência de um consenso acerca dos possíveis impactos provenientes de ajustes fiscais.

4 Entre as várias medidas realizadas nessa emenda, destaca-se o artigo 107, no qual ficam constituídos, para cada exercício, limites individualizados para as despesas primárias do Poder Executivo, do Supremo Tribunal Federal, do Superior Tribunal de Justiça, do Conselho Nacional de Justiça, da Justiça do Trabalho, da Justiça Federal, da Justiça Militar da União, da Justiça Eleitoral e da Justiça do Distrito Federal e Territórios, no âmbito do Poder Judiciário, do Senado Federal, da Câmara dos Deputados e do Tribunal de Contas da União, no âmbito do Poder Legislativo, do Ministério Público da União e do Conselho Nacional do Ministério Público, bem como da Defensoria Pública da União. Segundo o artigo 108, o Presidente da República poderá propor, a partir do décimo exercício da vigência do Novo Regime Fiscal, projeto de lei complementar para alteração do método de correção dos limites de gastos.

5 Cardoso et al. (2019) realizam uma revisão de literatura sobre o enfoque da austeridade fiscal como política pública. 
Na literatura econômica, os precursores na utilização do capital público nos modelos de crescimento foram Arrow e Kurz (1970). Os autores atestaram que o capital público poderia afetar a economia diretamente, através das análises das variações do estoque de capital e do produto, e indiretamente, via produtividade marginal dos insumos. Sob outra ótica, Samuelson (1954) demonstra a importância do fornecimento de bens e serviços pelo poder públicos como componentes essenciais para os níveis de bem-estar das famílias. Seguindo essa linha, Baxter e King (1993) construíram uma função de utilidade composta por consumo privado, lazer e por uma função com consumo do governo e capital público.

Combinando ambas as abordagens supracitadas, a fim de destacar a importância dos gastos do governo para a economia brasileira, diversos trabalhos supõem que os gastos e investimentos do governo são componentes fundamentais tanto da função utilidade quanto da função de produção. ${ }^{6}$ Embora contenham os aspectos comuns mencionados, esses trabalhos apresentam uma ampla variedade de abordagens e temáticas específicas.

Outra dimensão importante refere-se à atuação do governo como promotor do crescimento econômico através da realização de políticas fiscais, como destacaram Romer (1986) e Lucas (1988). Por outro lado, os trabalhos de Barro (1990) e Barro e Sala-i-Martin (1992) evidenciaram a importância dos gastos públicos bem como do seu financiamento. Lansing (1988), analisando o papel ótimo da política fiscal num modelo de ciclos reais de negócios com taxas ótimas de impostos, empréstimos do governo e capital público produtivo, concluiu que as variáveis fiscais, escolhidas otimamente, funcionam como estabilizadores automáticos. Contudo, uma vertente da literatura tem focado na hipótese de contração fiscal expansionista. Tal vertente destacou-se desde Giavazzi e Pagano (1990) a trabalhos mais recentes como Schneider et al. (2016) e Bova et al. (2018).

Ressalta-se ainda que a gestão e a política fiscal representam importantes papéis na condução da política econômica não apenas devido à concentração de forças para tornar a dívida pública sustentável, mas também na busca de regras bem definidas para o controle das contas pú- 
blicas. Para Gerardo (2010, p. 12), "as decisões dos agentes econômicos quanto ao nível e ao financiamento do déficit público têm reflexos sobre a taxa de juros e a inflação". Ao afetar a dívida pública essas variáveis influenciam as expectativas dos agentes, inclusive no que diz respeito à sustentabilidade.

Admitindo-se que consumo e investimento públicos em certa medida se associam, respectivamente, às ofertas de bens públicos e capital público, Chatterjee e Ghosh (2011) afirmaram que reformas fiscais realizadas pelos governos e que imponham limites sobre esses agregados podem, em princípio, afetar o nível de bem-estar e a eficiência da economia.

A partir do exposto, este artigo avalia os efeitos da EC 95/2016 tanto em relação à gestão fiscal e ao crescimento econômico quanto ao bem-estar das famílias. Utiliza-se um modelo dinâmico de equilíbrio geral com agentes heterogêneos calibrado com parâmetros reais da economia brasileira de forma a refletir o cenário de estagnação atual. O modelo utilizado considera que gastos e investimentos públicos afetam o bem- estar das famílias e a produtividade das firmas. Admite-se, ainda, a possibilidade de congestão nos serviços públicos.

Este artigo está organizado em mais quatro seções, além desta introdutória. A próxima seção descreve o modelo a ser utilizado. A terceira seção versa sobre os dados, bem como apresenta os parâmetros calibrados. A quarta seção apresenta e discute os resultados simulados. Por fim, na última seção são tecidos comentários e considerações finais.

\section{Modelo teórico}

Esta seção apresenta o modelo de equilíbrio geral dinâmico computável de acordo com a combinação dos modelos de Barro (1990) e Turnovsky (1996). Figura-se, portanto, como um modelo de crescimento neoclássico, no qual a economia modelada caracteriza-se por ser do tipo fechada ${ }^{7}$ e com governo.

7 A escolha por uma economia fechada vai em direção à linha de pensamento defendida em Holland (2019), no qual explicita que a abertura comercial brasileira não apresentou mudanças relevantes ao longo do tempo e, portanto, não se esperam mudanças estruturais relevantes sobre as variáveis macroeconômicas ao usar um modelo específico para análise do comportamento da economia brasileira. 


\subsection{Famílias}

Considera-se a existência de dois tipos de agentes que se beneficiam dos serviços fornecidos pelo governo não apenas através da disponibilidade de infraestrutura pública (estradas, energia, comunicações, aeroportos etc.), mas também dos serviços públicos (praças e parques, museus, eventos sociais etc.). A especificação da congestão dos serviços públicos é uma variante daquela encontrada em Turnovsky (1996), Eicher e Turnovsky (2000), Pintea e Turnovsky (2006).

\subsubsection{Famílias sem capacidade de poupança}

A família do tipo $p$ caracteriza-se por não possuir capacidade para poupar e/ou investir na economia. É dotada de uma unidade de tempo alocada em trabalho $\left(h_{p t}\right)$ e lazer $\left(1-h_{p t}\right), \operatorname{com} h_{p t} \in[0,1]$. Consome do setor privado $\left(c_{p t}\right)$ e do público $\left(c g_{p t}^{S}\right)$, onde parte dos serviços públicos são sujeitos à congestão no uso. Os indivíduos obtêm utilidade a partir do consumo e lazer, dado um fator de desconto intertemporal $\beta \in(0,1)$. A função utilidade é dada por (1):

$$
\begin{aligned}
& U_{p}\left(c_{p t}, h_{p t}, c g_{p, t}^{S}\right)=\sum_{t=0}^{\infty} \beta^{t}(1+n)^{t}\left\{\ln \left(c_{p t}+\mu c g_{p t}^{S}\right)+\psi_{p} \ln \left(1-h_{p t}\right)\right\}, \\
& \mu \geq 0
\end{aligned}
$$

onde $\mu$ representa a proporção do consumo público no consumo total, $n$ a taxa de crescimento populacional, $\psi_{p}$ evidencia o quanto o indivíduo do tipo $p$ valora o lazer, $h_{p t}$ são as horas médias de trabalho que as famílias $p$ empregam na produção. Supõe-se que o consumo e o trabalho são tributados com base nas respectivas alíquotas, $\tau_{c p}$ e $\tau_{h p}$.

Assim, a restrição orçamentária das famílias do tipo $p$ será dada da seguinte forma:

$$
\left(1+\tau_{c p}\right) c_{p t}=\left(1-\tau_{h p}\right) \xi_{p} w_{t} h_{p t}+t r_{p t}
$$

onde $\xi_{p}$ refere-se à produtividade dos agentes e $w_{t}$ representa o salário médio bruto por hora de trabalho, isto é, antes da cobrança dos impostos, e a variável $t r_{p t}$ constitui as transferências destinadas às famílias do tipo $p$. 


\subsubsection{Famílias com acesso a crédito e com capacidade de poupança}

Tal como as famílias do tipo $p$, as famílias do tipo $q$, ou famílias com capacidade de poupar/investir, são dotadas com uma unidade de tempo alocada em trabalho e lazer. Também consomem do setor privado $\left(c_{q t}\right)$ e do público $\left(c g_{q t}^{S}\right)$. As famílias do tipo $q$ têm preferência sobre um fluxo de utilidade de acordo com (3):

$$
\begin{aligned}
& U_{q}\left(c_{q t}, h_{q t}, c g_{q, t}^{S}\right)=\sum_{t=0}^{\infty} \beta^{t}(1+n)^{t}\left\{\ln \left(c_{q t}+\mu c g_{q t}^{S}\right)+\psi_{q} \ln \left(1-h_{q t}\right)\right\}, \\
& \mu \geq 0
\end{aligned}
$$

onde $\psi_{q}$ representa o quanto essas famílias ponderam o lazer na função de utilidade e $h_{q t}$ representa as horas médias de trabalho que essas famílias ofertam para a produção do único bem da economia.

Diferentemente das famílias do tipo $p$, essas famílias, no tempo $t$, são dotadas de um estoque de capital $\left(k_{t}\right)$ que lhes gera renda via aluguel às firmas $\left(r_{t} k_{t}\right)$, posse de títulos do governo $\left(b_{t}\right)$ remunerados à taxa $\rho_{t} b_{t}$, renda do trabalho $\left(\xi_{q} w_{t} h_{q t}\right)$, onde $\xi_{q}$ refere-se à produtividade desse agente, $\mathrm{e}$ transferências oriundas do governo $\left(t r_{q t}\right)$. Supõe-se que o consumo, o trabalho, o capital e os títulos são tributados com base nas respectivas alíquotas $\tau_{c q}, \tau_{h q}, \tau_{k}$ e $\tau_{b}$.

A família inicia com um estoque de capital físico $k_{0}$ e decide o quanto irá ampliar esse capital através de novos investimentos. A cada período o capital físico se deprecia a uma taxa $\delta$, com $0<\delta<1$ e cresce a uma taxa $(1+n)$. A lei de movimento do capital físico, portanto, será dada por:

$$
(1+n) k_{t+1}=(1-\delta) k_{t}+i_{t}
$$

Os gastos dos agentes com consumo privado $\left(c_{q t}\right)$, investimento $\left(i_{t}\right)$ e acumulação de títulos do governo $\left(b_{t+1}-b_{t}\right)$ são limitados, a cada período, pela restrição orçamentária descrita de acordo com (5) e levando em conta a lei de movimento do capital privado (4):

$$
\begin{aligned}
& \left(1+\tau_{c q}\right) c_{q t}+i_{t}+\left((1+n) b_{t+1}-b_{t}\right)=\left(1-\tau_{h q}\right) \xi_{q} w_{t} h_{q t}+\left(1-\tau_{k}\right) r_{t} k_{t}+ \\
& +\left(1-\tau_{b}\right) \rho_{t} b_{t}+t r_{q t}
\end{aligned}
$$


Cabe destacar que a maior parte dos serviços fornecidos pelo governo são fundamentais para a economia, pois aumentam diretamente a utilidade das famílias. Contudo, nem todos os serviços públicos fornecidos são não rivais e não excludentes. Portanto, nesse modelo assumiremos uma expressão para a congestão no consumo de bens públicos como uma variante daquela encontrada em Turnovsky (1996), para ambos os agentes, da seguinte forma:

$$
\begin{aligned}
& c g_{p, t}^{S}=\frac{C_{g t}}{N} \\
& c g_{q t}^{S}=\frac{C_{g t}}{N} \\
& N=N_{p}+N_{q}
\end{aligned}
$$

onde $N$ é o tamanho da população, $N_{p}$ é o número de famílias do tipo $p$ e $N_{q}$, o número de famílias do tipo $q$.

Dado que as famílias vivem infinitamente, estas desejam maximizar o seu fluxo de utilidade a cada período, respeitando suas respectivas restrições orçamentárias. Assim, o problema das famílias do tipo $p$ será maximizar (1) sujeito à (2) e o das famílias do tipo q será maximizar (3) sujeito à (5). Ambas levando em consideração (6) e (7), respectivamente.

\subsection{Firmas}

A firma representativa produz um bem final através de uma função Cobb-Douglas de acordo com Eicher e Turnovsky (2000). Para produzir, $Y_{t}$ utiliza do capital privado $\left(K_{t}\right)$, trabalho $\left(H_{t}\right)$ e serviços fornecidos pelo estoque de capital público $\left(K_{g, t}^{S}\right)$. Da mesma forma como em Uzawa (1961), assume-se que a função de produção apresenta crescimento da produtividade de modo a possibilitar que a economia cresça em termos per capita no longo prazo. O progresso tecnológico $\left(A_{t}\right)$ será, portanto, do tipo aumentador de trabalho ${ }^{8}$ e crescerá a uma taxa $(1+g)$. Dessa forma, a função de produção será dada por:

8 Barro e Sala-i-Martin (2004) explicam que o termo progresso tecnológico aumentador de trabalho se deve ao fato de este aumentar o produto na mesma direção do aumento no estoque de trabalho, uma vez que aparece na função de produção como um múltiplo deste último. 


$$
Y_{t}=A K_{t}^{\sigma_{K}}\left(A_{t} H_{t}\right)^{1-\sigma_{K}}\left(K_{g, t}^{S}\right)^{\gamma}
$$

$\operatorname{com} K_{g, t}^{S}=\frac{K_{g t}}{K_{t}}$

Assume-se que a firma privada representativa maximiza lucro $\left(\Pi_{t}\right)$, de forma que no equilíbrio o retorno bruto do capital seja igual a $r_{t}$ e a taxa de salário antes da incidência do imposto seja $w_{t}$. Portanto, o problema da firma representativa, em cada instante $t$, será:

$$
\max _{K_{t}, H_{t}} \Pi_{t}=\left\{A K_{t}^{\sigma_{K}}\left(A_{t} H_{t}\right)^{1-\sigma_{K}}\left(K_{g, t}^{S}\right)^{\gamma}-w_{t} H_{t}-r_{t} K_{t}\right\}
$$

\subsection{0 governo}

A receita tributária do governo $\left(T_{t}\right)$ é composta basicamente de impostos incidentes sobre o consumo das famílias, $\tau_{c p} C_{p t}$ e $\tau_{c q} C_{q t}$, as rendas dos trabalhos, $\tau_{h p} w_{p t} H_{p t}$ e $\tau_{h q} w_{q t} H_{q t}$, os rendimentos do capital privado, $\tau_{k} r_{t} K_{t}^{9}$ e sobre o rendimento dos títulos públicos, $\tau_{b} \rho_{t} B_{t}$, de posse das famílias. Além dessas fontes de receitas, o governo pode também arrecadar recursos através da emissão de novos títulos da dívida pública. Assim, dada a lei de movimento do capital público, conforme equação (13), a restrição orçamentária do governo, bem como a equação que determina a arrecadação tributária, pode ser resumida, respectivamente nas equações (11) e (12):

$$
\begin{aligned}
& T_{t}+B_{t+1}-B_{t}=C_{g t}+I_{g t}+T R_{p t}+T R_{q t}+\rho_{t} B_{t} \\
& T_{t}=\tau_{c p} C_{p t}+\tau_{c q} C_{q t}+\tau_{h p} \xi_{p} w_{t} H_{p t}+\tau_{h q} \xi_{q} w_{t} H_{q t}+\tau_{k} r_{t} K_{t}+\tau_{b} \rho_{t} B_{t} \\
& K_{g t+1}=\left(1-\delta_{g}\right) K_{g t}+I_{g t}
\end{aligned}
$$

onde $B_{t}=N_{q t} b_{t}$ representa o estoque de títulos públicos agregados.

O governo aloca uma fração do produto agregado da economia em cada um de seus gastos, a lembrar, consumo público, investimento público e

9 A tributação sobre o capital engloba desde impostos diretos e indiretos como contribuições e taxas. Por exemplo: Imposto de Renda Pessoa Jurídica (IRPJ), Imposto sobre Operações Financeiras (IOF), Contribuição para Financiamento da Seguridade Social (COFINS), CSLL, PIS/PASEP, Taxas Federais, entre outros. 
transferências. Assim, as políticas fiscais são dadas, respectivamente, por: $C_{g t}=\alpha_{g} Y_{t}, I_{g t}=\alpha_{I} Y_{t}, T R_{p t}=\alpha_{p} Y_{t}$ e $T R_{q t}=\alpha_{q} Y_{t}$. Onde $\alpha_{g}, \alpha_{I}, \alpha_{p}$, e $\alpha_{q}$ são os parâmetros de política.

\subsection{Comportamento de equilíbrio da economia agregada}

O produto total dessa economia provém a cada período das interações entre os agentes definidos ao longo desta subseção. Então, dada a política fiscal adotada pelo governo $\left\{\tau_{c p} ; \tau_{c q} ; \tau_{h p} ; \tau_{h q} ; \tau_{k} ; \tau_{b} ; \alpha_{g} ; \alpha_{l} ; \alpha_{p} ; \alpha_{q}\right\}_{t=0}^{\infty}$, o equilíbrio competitivo será caracterizado por uma sequência de decisões das famílias $\left\{c_{p t} ; c_{q t} ; i_{t} ; h_{p t} ; h_{q t} ; b_{t+1}\right\}_{t=0}^{\infty}$; por uma sequência ótima de estoques de capital privado e público $\left\{K_{t} ; K_{g t}\right\}_{t=0}^{\infty}$; por uma sequência de preços dos fatores $\left\{w_{p t} ; w_{q t} ; r_{t}\right\}_{t=0}^{\infty} ;$ e pela taxa de juros da dívida pública $\left\{\rho_{t}\right\}_{t=0}^{\infty}$, que é compatível com a) a maximização do problema do consumidor do tipo $p$; b) a maximização do problema do consumidor do tipo q; c) o problema de maximização da firma; d) as condições de agregação das decisões individuais em agregadas $\left(C_{p t}=N_{p} c_{p t} ; C_{q t}=N_{q} c_{q t} ; C_{t}=C_{p t}+C_{q t} ; K_{t}=N_{q} k_{t}\right.$; $\left.\left.T R_{p t}=N_{p} t r_{p t} ; T R_{q t}=N_{q} t r_{q t} I_{t}=N_{q} i ; B_{t}=N_{q} b_{t} ; H_{p t}=N_{p} h_{p t} ; H_{q t}=N_{q} h_{q t}\right) ; \mathrm{e}\right)$ a restrição orçamentária do governo; e f) a restrição de recursos da economia: $C_{t}+C_{g t}+I_{t}+I_{g t}=A K_{t}^{\sigma_{K}}\left(A_{t} H_{t}\right)^{1-\sigma_{K}}\left(K_{g, t}^{S}\right)^{\gamma}$.

\subsection{Análises de bem-estar}

Considera-se o estado estacionário das políticas fiscais conforme seção 2.4. Para mensurar a variação de bem-estar gerada por alterações nas políticas fiscais empregou-se uma metodologia tradicional na literatura. Esta segue, por exemplo, Chari et al. (1994; 1995) e Pereira e Ferreira (2008; 2011). A medida corresponde ao percentual de mudança no consumo privado $(x)$ necessário para obter o mesmo nível de utilidade que a simulação de política (DP), mantendo-se as horas de trabalho e o consumo de serviços públicos em seus níveis de estado estacionário (AP). Deve, portanto, satisfazer a seguinte equação:

$$
\begin{aligned}
& \sum_{t=0}^{\infty} \beta^{t}(1+n)^{t}\left\{\ln \left(c_{i t}^{A P}(1+x)+\mu_{i}\left(c g_{i t}^{S}\right)^{A P}\right)+\psi_{i} \ln \left(1-h_{i t}^{A P}\right)\right\}= \\
& =\sum_{t=0}^{\infty} \beta^{t}(1+n)^{t}\left\{\ln \left(c_{i t}^{D P}+\mu_{i}\left(c g_{i t}^{S}\right)^{D P}\right)+\psi_{i} \ln \left(1-h_{i t}^{D P}\right)\right\}
\end{aligned}
$$


onde: $i=p, q, A P=$ Antes da Política e $D P=$ Depois da política.

\section{Calibragem}

A calibração dos parâmetros segue, em grande medida, Gomes et al. (2019). ${ }^{10}$ Esse processo utiliza dados oficiais das Contas Nacionais, disponíveis no Instituto Brasileiro de Geografia e Estatística (IBGE), da Pesquisa Nacional por Amostragem de Domicílios (PNAD) referente ao ano de 2014, do Portal da Transparência do Governo Federal e dos Relatórios Gerenciais da Secretaria da Receita Federal (SRF).

\subsection{Divisão das famílias}

A classificação das famílias considera tanto o rendimento domiciliar per capita quanto o acesso, ou não, a ativos financeiros, tais como poupança, juros, dividendos e aluguéis, assim como a posse de bens móveis e imóveis. Ao possuir qualquer ativo a família é classificada como do tipo $q$. Como critério de divisão pela renda adotou-se o critério de $1 / 4$ do salário mínimo, ${ }^{11}$ sendo os mais pobres classificados com tipo p. A divisão das famílias segue Gomes et al. (2019), que aplicam o método presente em Barros et al. (2007) para reduzir o viés de identificação das famílias.

As famílias do tipo $p$ ocupam $16,73 \%$ dos domicílios, enquanto o tipo $q$ representa $83,27 \%$. Logo, $L_{p}=0,1673$ e $L_{q}=0,8327$. A partir de dados da Penn World Table (PWT) para as horas trabalhadas anuais médias por trabalhador brasileiro, referentes ao período de 2006 a 2014, chega-se a $H=0,293028$. Dados da PNAD para o ano de 2014 indicam que o total de horas médias semanais trabalhadas pelas famílias do tipo $p$ e $q$ são, respectivamente, 22,24 horas e 24,69 horas. Então, dados $L_{p}, L_{q}$ e $H$, têm-se $h_{p}=0,338$ e $h_{q}=0,321$. Tais valores representam, aproximadamente, um terço das suas horas diárias disponíveis.

$10 \mathrm{O}$ processo descrito neste artigo apresenta-se resumido. Para maiores detalhes, ver a referência na íntegra.

11 A literatura de pobreza define que $1 / 4$ de salário mínimo é valor que delimita a linha de indulgência. Medidas de linhas de pobreza baseadas em frações do salário mínimo são controversas, contudo, são bastante utilizadas pelo governo como medida de elegibilidade de programas sociais (Loureiro et al. 2010, p. 7). 
Esse resultado assemelha-se ao apontado por Cooley e Prescott (1995) para a economia americana.

\subsection{Contas nacionais}

Os parâmetros do modelo serão subdivididos em: a) parâmetros de tecnologia $\left.\left(\sigma_{k}, \xi_{p}, \xi_{q}, \delta, \delta_{g}, \gamma, A, n, g\right) ; b\right)$ parâmetros fiscais $\left\{\tau_{c p}, \tau_{c q}, \tau_{h p}, \tau_{h q}, \tau_{k}, \tau_{b}, \alpha_{g}, \alpha_{I}\right.$, $\left.\alpha_{p}, \alpha_{q}, \alpha_{b}\right)$; e c) parâmetros de preferências $\left(\beta, \mu, \psi_{p}, \psi_{q}\right)$. A Tabela 1 mostra as principais variáveis macroeconômicas como proporção do PIB, para o ano de 2014.

Tabela 1 Agregados macroeconômicos em relação ao PIB (2014)

\begin{tabular}{rr|r|r|r}
\hline $\boldsymbol{C} / \boldsymbol{Y}$ & $\mathbf{C g} / \mathbf{Y}$ & $\mathbf{g} / \boldsymbol{Y}$ & $\boldsymbol{I} \mathbf{Y}$ & $\mathbf{B} / \mathbf{Y}$ \\
\hline 0,6296 & 0,1915 & 0,0297 & 0,1492 & 0,3259 \\
\hline
\end{tabular}

Fonte: Elaboração própria.

Obs.: C (Consumo privado); $\mathrm{C}_{\mathrm{g}}$ (Consumo do governo); I (Investimento do governo); I (Investimento privado) e B (Estoque da dívida pública).

\subsubsection{Parâmetros de tecnologia}

Para as taxas de depreciação média dos capitais público e privado aplicaram-se dados do IBGE e do Instituto de Pesquisa Econômica Aplicada (IPEADATA) nas equações das leis de movimento em estado estacionário. As médias das médias das frações $\left(I_{g t} / K_{g t}\right)$ e $\left(I_{t} / K_{t}\right)$ entre 1998 e 2008 são, respectivamente, 0,0509 e 0,07869 . No mesmo período, a taxa de crescimento populacional foi de $0,014767 .{ }^{12}$ Para a taxa de crescimento da produtividade do trabalho adotou-se a média da taxa de crescimento da relação PIB real ${ }^{13}$ sobre a $\operatorname{PEA}^{14}(0,005595)$. Assim, têm-se $\delta_{g}=0,0305$ e $\delta=0,0581$.

12 Para os anos de 1997, 1998 e 1999 utilizaram-se estimativas da população e para o ano 2000, o resultado censitário. Já para o período de 2001 a 2008 utilizou-se a taxa de crescimento da população residente.

13 A série anual do PIB real é obtida a partir da soma dos trimestres das Contas Nacionais Trimestrais do IBGE com valores encadeados a preços de 1995.

14 População Economicamente Ativa. Dados do IPEADATA. Para os anos de 2000 e 2010 são utilizados dados censitários do IBGE. 
O efeito do capital público de infraestrutura sobre o produto da economia é expresso pelo parâmetro $\gamma$. Neste trabalho adotou-se o valor obtido por Ferreira (1993) e Ferreira e Nascimento (2006) de $\gamma=0,09 .{ }^{15}$ A escotha segue trabalhos afins na literatura nacional, por exemplo, Bezerra et al. (2014) e Pereira e Ferreira (2010). A fração da remuneração do capital no produto é medida como a soma do excedente operacional bruto com um terço do rendimento misto bruto como proporção do PIB a custo de fatores. ${ }^{16}$ A partir de dados do IBGE para o ano de 2014 obteve-se $\sigma_{k}=$ 0,422094 . Assim, a fração da renda do trabalho é de $\left(1-\sigma_{k}\right)=0,577906$. Ambos os valores se aproximam daqueles encontrados na literatura. ${ }^{17}$

A taxa de crescimento da produtividade do trabalho, por sua vez, é obtida de acordo com a média da taxa de crescimento da relação PIB real ${ }^{18}$ sobre a PEA ${ }^{19}$ entre 1995 e 2013, de acordo com dados do IBGE e do IPEADATA. Assim, $g=0,0111$. A produtividade total dos fatores $(A)$, por sua vez, foi calibrada de maneira que o produto estacionário em unidades de eficiência seja igual à unidade. Portanto, $A=1,5044$. Para o ano de 2014, a taxa de crescimento da população residente foi igual a $n=0,0086$. A Tabela 2 resume os valores dos parâmetros desta subseção.

Tabela 2 Síntese da calibração dos parâmetros tecnológicos (valores absolutos)

\begin{tabular}{rr|r|r|r|r}
\hline $\boldsymbol{\sigma}_{\boldsymbol{K}}$ & $\boldsymbol{n}$ & $\boldsymbol{\delta}_{\boldsymbol{g}}$ & $\boldsymbol{\delta}$ & $\boldsymbol{\gamma}$ & $\boldsymbol{A}$ \\
\hline 0,4220 & 0,0086 & 0,0305 & 0,0581 & 0,09 & 1,5044 \\
\hline
\end{tabular}

Fonte: Elaboração própria.

\subsubsection{Parâmetros fiscais}

Para o cálculo das alíquotas $\tau_{c}$, $\tau_{h}$ e $\tau_{k}$ são utilizados dados das contas nacionais disponibilizados pelo IBGE e da SRFB. A alíquota de imposto sobre

15 Para mais detalhes quanto ao parâmetro de tecnologia $(\gamma)$, ver a discussão em Ferreira e Nascimento (2006).

16 O PIB a custo de fatores é obtido subtraindo do PIB os impostos e subsídios à produção e importação.

17 Santana et al. (2012), Bezerra et al. (2018), Campos e Pereira (2016) e Pereira e Ferreira (2010), este último utiliza dados para a economia americana.

18 A série anual do PIB real é obtida a partir da soma dos trimestres das Contas Nacionais Trimestrais do IBGE com valores encadeados a preços de 1995.

19 Dados do IPEADATA, para os anos de 2000 e 2010 são utilizados dados censitários do IBGE. 
o consumo pode ser calculada de acordo com a fração da receita tributária sobre o consumo final das famílias. Em 2014 a receita tributária sobre o consumo foi de $9,13 \%$ do PIB, já o consumo final das famílias foi de $62,95 \%$ do PIB, resultando em $\tau_{c}=0,1451$. Já a receita tributária incidente sobre o trabalho foi de $8,98 \%$ do PIB, $\left(\tau_{h t} w_{t} H_{t} / Y_{t}=0,0898\right)$. Logo, tem-se $\tau_{h}=0,1555$.

Assumindo-se que os agentes mais pobres (tipo $p$ ) pagam apenas a alíquota mínima do INSS, equivalente a $8 \%$, ou seja, $\tau_{h p}=0,08$, e dado que receita tributária no PIB pode ser representada pela seguinte expressão $\tau_{h p} \xi_{p} w h_{p} L_{p}+\tau_{h q} \xi_{q} w h_{q} L_{q}=\left(\right.$ Rec.Trib.sobre o Trabalho $\left./ Y_{t}\right)$, determina-se 0 valor de $\tau_{h q}=0,1628$.

De acordo com os dados do relatório mensal da dívida pública da Secretaria do Tesouro Nacional (STN), em dezembro de 2014, o prazo de vencimento da dívida pública mobiliária federal interna (DPMFi) é de 12 meses para $24,64 \%$ dos títulos, de 1 a 2 anos para $17,56 \%$ dos títulos e acima de 2 anos para os demais. Seguindo a Lei n ${ }^{\circ} 11.033$ de 21 de dezembro de 2004, existe incidência de Imposto de Renda (IR) sobre os títulos de $21,25 \%$ (média entre as aplicações com prazo até 180 dias e de 181 a 360 dias), 17,5\% para aplicações entre 361 e 720 dias, e de $15 \%$ acima de 720 dias. A média ponderada entre prazos e alíquotas determina uma alíquota média de $16,97 \%$ para o Imposto de Renda sobre títulos e com zero de alíquota de Imposto sobre Operações Financeiras (IOF). Obtém-se, portanto, $\tau_{b}=0,1697$.

A receita tributária sobre capital e títulos como proporção do produto é de $13,78 \%$. A carga tributária total é de $31,90 \%$ do PIB. A soma da arrecadação tributária dos rendimentos de capital e de títulos pode ser escrita como uma fração do PIB da seguinte forma $\left(\tau_{k} r_{t} K_{t}+\tau_{b} \rho_{t} B_{t}\right) / Y_{t}$. A partir do resultado encontrado para a elasticidade do produto em relação ao capital, é possível obter a alíquota de imposto sobre o capital:

$$
\tau_{k}=\frac{\text { Receitatrib. sobre rend.de capital etitulos }(\% P I B)-\left(\tau_{b} \rho_{t} B_{t} / Y_{t}\right)}{\sigma K}
$$

O cálculo dessa alíquota depende do estoque de dívida pública $\left(B_{t}\right)$ e da taxa de juros real da dívida pública $\left(\rho_{t}\right)$. Segundo dados do Bacen e do IBGE, em dezembro de 2014 a DLSP era de 32,58\% do PIB. A série da taxa nominal de juros da dívida pública é calculada a partir da relação 
$\left(\rho_{t}^{n} B_{t} / B_{t}\right)$, onde $\rho_{t}^{n} B_{t}$ é dado pelo fluxo mensal de juros nominais acumulados em 12 meses obtido com dados do Bacen, e $B_{t}$ é o fluxo da DLSP. A série da taxa de juros real da dívida pública é construída a partir da expressão $\rho_{t}=\left(\rho_{t}^{n}-\pi_{t}\right) /\left(1+\pi_{t}\right)$. Onde $\pi_{t}$ é a inflação medida pelo Índice de Preços ao Consumidor Amplo (IPCA) acumulado em 12 meses, obtido no Bacen. A taxa média de juros reais da dívida púbica entre janeiro de $2008 \mathrm{e}$ dezembro de 2011 é $\rho=7,57 \%$, resultando em $\tau_{k}=31,65 \%$.

Os parâmetros $\alpha_{g}, \alpha_{I}$ e $\alpha_{b}$ são dados pelas frações dos gastos do governo em consumo, investimento do governo e DLSP no PIB, respectivamente. A proporção das transferências médias do governo para as famílias é $t r_{p t} / t r_{q t}=0,086999$. A partir da qual se determinam os valores das transferências para cada grupo de agentes. Assim, $\alpha_{p}=0,00608$. Similarmente, a partir da soma dos agregados macroeconômicos obtidos nas contas nacionais do IBGE determinam-se o consumo do governo e o investimento privado em relação ao PIB, dados por $\alpha_{g}=0,191535$ e $\alpha_{I}=0,0296836$.

Tabela 3 Síntese da calibração dos parâmetros fiscais (valores absolutos)

\begin{tabular}{rr|r|r|r|r|r|r|r}
\hline$\tau_{c}$ & $\tau_{h p}$ & $\tau_{h q}$ & $\tau_{b}$ & $\tau_{k}$ & $\alpha_{g}$ & $\alpha_{l}$ & $\boldsymbol{\alpha}_{b}$ & $\boldsymbol{\alpha}_{p}$ \\
\hline 0,1451 & 0,08 & 0,1628 & 0,1697 & 0,3165 & 0,1915 & 0,0296 & 0,3258 & 0,0061 \\
\hline
\end{tabular}

Fonte: Elaboração própria.

\subsubsection{Parâmetros de preferências}

O parâmetro $\mu=0,5$ segue a escolha conservadora como em Bezerra et al. (2014), Santana et al. (2012) e Ferreira e Nascimento (2006). O fator de desconto intertemporal $(\beta)$ é dado pela solução de estado estacionário, $\beta=\frac{1+g}{1+\rho\left(1-\tau_{b}\right)}$. Dados os valores de $g=0,02166, \rho=0,08812 \mathrm{e}$ $\tau_{b}=0,17437$, encontra-se o valor de $\beta=0,952369$. Por fim, determina-se que $\xi_{p}=0,4540, \xi_{q}=1$ e $\psi_{p}=\psi_{q}=1,2848$.

Tabela 4 Síntese da calibração dos parâmetros preferências (valores absolutos)

\begin{tabular}{|c|c|c|c|c|c|}
\hline$\mu$ & $\beta$ & $\psi_{p}$ & $\psi_{q}$ & $\xi_{p}$ & $\xi_{q}$ \\
\hline 0,5 & 0,95237 & 1,2848 & 1,2848 & 0,454 & 1 \\
\hline
\end{tabular}

Fonte: Elaboração própria. 


\section{Resultados}

As simulações foram divididas em duas subseções. Primeiramente, simulamos aumentos de produtividade em um ambiente com e sem a implementação da EC 95/2016. A simulação de um cenário sem a implementação funciona como benchmarking e visa captar o real efeito da EC 95/2016. Em seguida, consideram-se simulações de diferentes políticas alternativas à EC 95/2016. Uma vez que a EC 95/2016 pode ser revista depois de passados 10 anos de seu início, os exercícios tanto dos cenários com a implementação da EC 95/2016 quanto das políticas alternativas foram simulados com período de vigência de 10 e de 20 anos. A fim de facilitar o entendimento prévio dos cenários de produtividade e das simulações, elaboraram-se quadros-resumo. O Quadro 1 especifica os cenários de produtividade. Já o Quadro 2, acerca das políticas, encontra-se no início de sua respectiva subseção.

\section{Quadro 1 Descrição resumo dos cenários de produtividade}

\begin{tabular}{l|l}
\hline Cenário & Descrição \\
\hline g00 & Taxa de crescimento da produtividade igual a zero. \\
\hline g05 & $\begin{array}{l}\text { Taxa de crescimento da produtividade igual à metade da taxa de crescimento média } \\
\text { observada no período entre 1996 e 2014*. }\end{array}$ \\
\hline g11 & $\begin{array}{l}\text { Taxa de crescimento da produtividade igual à taxa de crescimento média observada no } \\
\text { período entre } 1996 \text { e } 2014 .\end{array}$ \\
\hline 22 & $\begin{array}{l}\text { Taxa de crescimento da produtividade igual ao dobro da taxa de crescimento média } \\
\text { observada no período entre } 1996 \text { e 2014. }\end{array}$ \\
\hline
\end{tabular}

Fonte: Elaboração própria.

Notas: * Taxa de crescimento média observada no período entre 1996 e 2014 igual a 1,1\%.

\subsection{Cenários macroeconômicos com ganhos de produtividade}

\subsubsection{Cenário macroeconômico com ganhos de produtividade na ausência da EC 95/2016}

Inicialmente avaliam-se os impactos sobre as variáveis agregadas no caso de haver apenas crescimento da produtividade, conforme Quadro 1. Tal crescimento pode ser derivado de diferentes formas, por exemplo, de incrementos na tecnologia utilizada, da melhoria nos processos de produção 
e/ou de uma melhor capacitação da força de trabalho. Considerando a ausência da EC 95/2016, busca-se responder o que aconteceria se houvesse um ganho inesperado de produtividade. Para tanto, simulam-se os quatro cenários de crescimento de produtividade: $g 00, g 05, g 11$ e g22.

Dado o estado estacionário da economia, pela Tabela 5 observa-se que na ausência de crescimento da produtividade nada ocorrerá uma vez que não houve nenhum choque na economia. Contudo, à medida que os ganhos de produtividade aumentam, observam-se ganhos crescentes e expressivos de bem-estar individuais e agregados.

Tabela 5 Cenários de crescimento sem a EC 95/2016 (aumentos de produtividade)

\begin{tabular}{lrrrrrr}
\hline Variáveis & E.E. & g00 & g05 & g11 & g22 \\
\hline Resultado Primário/PIB & 0,0168 & 0,0168 & 0,0165 & 0,0162 & 0,0158 \\
\hline Resultado Nominal/PIB* & $-0,0028$ & $-0,0028$ & $-0,0044$ & $-0,0059$ & $-0,0085$ \\
\hline Produto & 1,0000 & 1,0000 & 0,9551 & 0,9154 & 0,8478 \\
\hline Bem-estar & & & & \\
\hline Individual & Agentes p & 0,0000 & 15,0945 & 31,9133 & 71,5143 \\
\hline & Agentes q & 0,0000 & 12,5644 & 26,5513 & 59,4386 \\
\hline Agregado & Agente Típico** & $\mathbf{0 , 0 0 0 0}$ & 12,9876 & 27,4482 & 61,4586 \\
\hline
\end{tabular}

Fonte: Elaboração própria.

Notas: * No resultado nominal, diferentemente do resultado primário, consideram-se as receitas e despesas com juros. ${ }^{* *} O$ bem-estar agregado, referente ao agente típico da economia, é igual à soma das medidas de bem-estar individuais ponderados pelas respectivas frações da população, $\mathrm{L}_{p}$ e $\mathrm{L}_{q}$. E.E é $o$ estado estacionário inicial do modelo.

Em relação aos resultados fiscais, os aumentos de produtividade adquiridos proporcionam a obtenção de resultados primários positivos no longo prazo. No entanto, para manter o alto nível de produtividade exigido pela economia, o governo deve elevar os retornos do capital público de modo a haver crescimento de bem-estar associado à presença de déficits nominais (\%PIB) inferiores a $1 \%$.

Ressalta-se que os ganhos de bem-estar são determinados pelas variáveis per capita e, portanto, refletem os aumentos da taxa de crescimento da população e da produtividade conjuntamente, $(1+n)(1+g)$. Vale ressaltar que esses mesmos fatores provocam queda no produto per capita em unidade de eficiência. A seguir, trataremos casos nos quais se consideram reformas fiscais, a fim de simular a vigência da EC 95/2016 (10 ou 20 anos) conjuntamente com crescimento de produtividade da economia. 


\subsubsection{Cenário macroeconômico com ganhos de produtividade na presença da EC 95/2016 (10 e 20 anos)}

Durante a vigência da EC 95/2016 consideramos constantes o consumo e os investimentos do governo bem como as transferências para as famílias. Durante essa política a dívida pública permaneceu variando de modo a equilibrar o orçamento do governo. Na Tabela 6 dispõem-se os resultados dessas simulações.

No tocante à gestão fiscal os resultados apontam que seriam obtidas reduções consideráveis da dívida pública, a lembrar, dívida líquida como proporção do PIB, e dos resultados fiscais, primário e nominal. Além disso, tais resultados são potencializados à medida que a produtividade aumenta. Os ganhos de bem-estar gerados pela EC 95/2016 estão intrinsecamente ligados aos ganhos de produtividade. Ademais, no cenário sem crescimento de produtividade, observaram-se perdas de bem-estar para os agentes do tipo $p$ em ambos os períodos de vigência da EC/95, sendo essas perdas maiores com o aumento do período de vigência para 20 anos.

Comparativamente com a situação sem a EC 95/2016 apresentada na Tabela 5 , os agentes do tipo $q$ terão seus ganhos elevados. Tendo acesso ao crédito, esses ganhos devem-se, sobretudo, à possibilidade de aumento de seus rendimentos com as aplicações de recursos em títulos do governo de forma a salvaguardar seus investimentos durante o prazo de vigência da política.

Tabela 6 Cenário macroeconômico com a EC 95/2016 (10 anos e 20 anos)

\begin{tabular}{|c|c|c|c|c|c|c|c|c|c|c|}
\hline \multirow{2}{*}{$\begin{array}{l}\text { Variáveis } \\
\text { Vigência }\end{array}$} & \multicolumn{2}{|r|}{ E.E. } & \multicolumn{2}{|r|}{$g 00$} & \multicolumn{2}{|r|}{ g05 } & \multicolumn{2}{|r|}{ g11 } & \multicolumn{2}{|r|}{ g22 } \\
\hline & 10 anos & 20 anos & 10 anos & 20 anos & 10 anos & 20 anos & 10 anos & 20 anos & 10 anos & 20 anos \\
\hline Res. Prim./PIB & 0,0168 & 0,0168 & 0,0092 & $-0,0153$ & 0,0069 & $-0,0264$ & 0,0046 & $-0,0367$ & 0,0002 & $-0,0554$ \\
\hline Res. Nom./PIB* & ${ }^{*}-0,0028$ & $-0,0028$ & $-0,0015$ & 0,0025 & $-0,0018$ & 0,0070 & $-0,0016$ & 0,0133 & $-0,0001$ & 0,0299 \\
\hline Produto & 1,0000 & 1,0000 & 0,9816 & 0,9641 & 0,9357 & 0,9085 & 0,8944 & 0,8589 & 0,8226 & 0,7735 \\
\hline \multicolumn{11}{|l|}{ Bem-estar } \\
\hline \multirow[t]{2}{*}{ Individual } & Tipo $p$ & & $-3,4642$ & $-5,6350$ & 10,2850 & 6,4608 & 25,4808 & 19,7846 & 60,8207 & 50,6330 \\
\hline & Tipo q & & 0,9879 & 1,5650 & 13,9157 & 14,8935 & 28,3315 & 29,7269 & 62,3069 & 64,5659 \\
\hline Agregado & $\begin{array}{l}\text { Agente } \\
\text { Típico** }\end{array}$ & & 0,2432 & 0,3606 & 13,3084 & 13,4829 & 27,8547 & 28,0638 & 62,0583 & 62,2353 \\
\hline
\end{tabular}

Fonte: Elaboração própria.

Notas: * No resultado nominal, diferentemente do resultado primário, consideram-se as receitas e des- 
pesas com juros. ** O bem-estar agregado, referente ao agente típico da economia, é igual à soma das medidas de bem-estar individuais ponderados pelas respectivas frações da população, $\mathrm{L}_{p} e \mathrm{~L}_{q}$.

Dada a existência dos ciclos econômicos, dificilmente será possível garantir ganhos crescentes e sustentados de produtividade por longos períodos. Assim, caso não haja nenhum tipo de compensação para as famílias mais pobres, estas lograrão perdas consideráveis. Para simular tais compensações, políticas alternativas à EC 95/2016 com esse perfil são propostas na próxima subseção.

Diante de um cenário de estagnação da produtividade da economia (g00), a EC 95/2016 proporcionará no longo prazo uma queda brusca na relação dívida/PIB. Isso ocorre devido, sobretudo, à redução do consumo e dos investimentos do governo. Por outro lado, essa queda provoca diretamente uma deterioração do estoque de capital público da economia resultando, principalmente, na redução da oferta de bens públicos fornecidos às famílias, tais como saúde, educação e segurança, serviços essenciais para as famílias mais pobres.

A Tabela 7 apresenta um quadro comparativo entre as situações de ausência e presença da reforma fiscal (EC 95/2016) com prazo de vigência de 10 e 20 anos. As variações líquidas de bem-estar para as famílias do tipo $q$ aumentam à medida que a vigência do congelamento dos gastos públicos se amplia, bem como na presença de ganhos de produtividade crescentes. Por outro lado, observa-se um efeito contrário nas famílias do tipo $p$, para os quais os ganhos somente serão percebidos nas situações de ausência da EC 95/2016.

Tabela7 Ganhos líquidos de bem-estar com a EC 95/2016 Comparativamente com o cenário sem a EC 95/2016

\begin{tabular}{lrrrr}
\hline Prod. do trabalho & Sem a EC 95 & EC 95 10 anos & EC 95 20 anos \\
\hline g00 (agente $p$ ) & $x=0,0000$ & $\Delta \mathrm{x}=-3,4642$ & $\Delta \mathrm{x}=-5,6350$ \\
\hline $\boldsymbol{g 0 0}$ (agente $\boldsymbol{q}$ ) & $x=0,0000$ & $\Delta \mathrm{x}=0,9879$ & $\Delta \mathrm{x}=1,5650$ \\
\hline $\boldsymbol{g 0 5}$ (agente $\boldsymbol{p}$ ) & $x=15,0945$ & $\Delta \mathrm{x}=-4,8095$ & $\Delta \mathrm{x}=-8,6337$ \\
\hline $\boldsymbol{g 0 5}$ (agente $\boldsymbol{q}$ ) & $x=12,5644$ & $\Delta \mathrm{x}=1,3513$ & $\Delta \mathrm{x}=2,3291$ \\
\hline g11 (agente $\boldsymbol{p}$ ) & $x=31,9133$ & $\Delta \mathrm{x}=-6,4325$ & $\Delta \mathrm{x}=-12,1287$ \\
\hline g11 (agente $\boldsymbol{q}$ ) & $x=26,5513$ & $\Delta \mathrm{x}=1,7802$ & $\Delta \mathrm{x}=3,1756$ \\
\hline $\boldsymbol{g} 22$ (agente $\boldsymbol{p}$ ) & $x=71,5143$ & $\Delta \mathrm{x}=-10,6936$ & $\Delta \mathrm{x}=-20,8813$ \\
\hline $\boldsymbol{g} 22$ (agente $\boldsymbol{q}$ ) & $x=59,4386$ & $\Delta \mathrm{x}=2,8683$ & $\Delta \mathrm{x}=5,1273$ \\
\hline
\end{tabular}

Fonte: Elaboração própria. 


\subsection{Políticas alternativas à Emenda Constitucional 95/2016}

Dados os efeitos gerados pela EC 95/2016, sobretudo no que diz respeito aos agentes mais pobres, gerou-se a necessidade de propor políticas alternativas que evitem tais perdas ou pelo menos que as mitiguem. As próximas subseções tratam de diferentes alternativas que variam desde adaptações da EC 95/2016 a compensações para os agentes mais prejudicados. O Quadro 2 resume essas políticas.

\section{Quadro 2 Descrição-resumo das políticas alternativas à EC 95/2016}

\begin{tabular}{|c|c|}
\hline Políticas & Descrição \\
\hline PA1 & Investimentos públicos retornam ao patamar anterior à realização da EC 95/2016. \\
\hline PA2 & $\begin{array}{l}\text { Investimento do governo não é afetado pelo congelamento durante o período de vigên- } \\
\text { cia da EC 95/2016. }\end{array}$ \\
\hline PA3 & $\begin{array}{l}\text { Consumo do governo }\left(C_{g t}\right) \text {, investimento do governo }\left(l_{g t}\right) \text {, transferências para as famí- } \\
\text { lias }\left(T R_{p t} \text { e } T R_{q t}\right) \text { constantes. A razão dívida/PIB }\left(B_{t}\right) \text { acomoda a restrição orçamentária } \\
\text { do governo durante a vigência da EC } 95 / 2016 \text { e, após a vigência, o nível de transferên- } \\
\text { cias no PIB para as famílias tipo } q\left(T R_{q t}\right) \text { acomoda a restrição orçamentária. } \alpha_{p} \text { retorna } \\
\text { ao valor anterior à política. }\end{array}$ \\
\hline PA4 & $\begin{array}{l}\text { Consumo do governo }\left(C_{g t}\right) \text {, transferências para as famílias }\left(T R_{p t} \text { e } T R_{q t}\right) \text {, razão dívida/ } \\
\text { PIB }\left(B_{t}\right) \text { constantes. } 0 \text { investimento do governo }\left(I_{g t}\right) \text { acomoda a restrição orçamentária } \\
\text { do governo durante a vigência da EC } 95 / 2016 \text { e, após a vigência, o nível de transferên- } \\
\text { cias no PIB para as famílias tipo } q\left(T R_{q t}\right) \text { acomoda a restrição orçamentária. } \alpha_{p} \text { retorna } \\
\text { ao valor anterior à política. }\end{array}$ \\
\hline PA5 & $\begin{array}{l}\text { Mesma configuração da PA3 com compensação para os agentes do tipo } p \text {. No caso de } \\
\text { vigência da EC } 95 / 2016 \text { por } 10 \text { anos considerou-se que } \alpha_{p}^{D C}=1,39 * \alpha_{p}^{A C} \text { de tal forma } \\
\text { que esses agentes obtenham o mínimo de ganhos de bem-estar positivos e, da mesma } \\
\text { forma, } \alpha_{p}^{D C}=2^{*} \alpha_{p}^{A C} \text { no caso de vigência de } 20 \text { anos. }\end{array}$ \\
\hline PA6 & $\begin{array}{l}\text { Mesma configuração da PA4 com garantia de variação de bem-estar positiva mínima pa- } \\
\text { ra os agentes do tipo } p \text {. No caso de vigência da EC 95/2016 por } 10 \text { anos considerou-se } \\
\text { que } \alpha_{p}^{D C}=0,93^{*} \alpha_{p}^{A C} \text { de tal forma que esses agentes obtenham o mínimo de ganhos de } \\
\text { bem-estar positivos e, da mesma forma, } \alpha_{p}^{D C}=0,84 *{ }^{A C} \alpha_{p}^{A C} \text { no caso de vigência de } 20 \text { anos. }\end{array}$ \\
\hline
\end{tabular}

Fonte: Elaboração própria.

\subsubsection{Políticas alternativas com investimento público}

Na primeira política alternativa, doravante PA1, considerou-se a possibilidade de os investimentos públicos retornarem ao patamar anterior à realização da EC 95/2016. Já a Política Alternativa 2 (PA2) libera o investimento 
do governo da política de congelamento durante o período de vigência da EC 95/2016. Essa proposta se justifica pela importância do investimento público em infraestrutura no estímulo ao crescimento da economia, discutida na seção introdutória.

A Tabela 8 apresenta os resultados dessas políticas considerando dois cenários de produtividade da economia: $g 00$ e $g 11$.

Tabela 8 Políticas com investimento público alternativas à EC 95/2016 (10 e 20 anos) com e sem ganhos de produtividade

\begin{tabular}{|c|c|c|c|c|c|c|c|c|}
\hline \multirow{2}{*}{$\begin{array}{l}\text { Variáveis } \\
\text { Vigência }\end{array}$} & \multicolumn{2}{|c|}{$\operatorname{PA} 1(g 00)$} & \multicolumn{2}{|r|}{ PA1 (g11) } & \multicolumn{2}{|c|}{$\mathrm{PA} 2(\mathrm{~g} 00)$} & \multicolumn{2}{|c|}{ PA2 (g11) } \\
\hline & 10 anos & 20 anos & 10 anos & 20 anos & 10 anos & 20 anos & 10 anos & 20 anos \\
\hline Res.Prim./PIB & 0,0092 & $-0,0155$ & 0,0045 & $-0,0370$ & 0,0154 & 0,0141 & 0,0145 & 0,0119 \\
\hline Res. Nom./PIB* & $-0,0015$ & 0,0025 & $-0,0016$ & 0,0134 & $-0,0025$ & $-0,0023$ & $-0,0053$ & $-0,0043$ \\
\hline Produto & 0,9929 & 0,9863 & 0,9072 & 0,8945 & 1,0921 & 1,1862 & 1,0525 & 1,1725 \\
\hline \multicolumn{9}{|l|}{ Bem-estar } \\
\hline Agentes p & $-3,2163$ & $-5,2987$ & 25,9652 & 20,6284 & $-0,4592$ & $-0,4937$ & 31,4569 & 29,8649 \\
\hline Agentes q & 1,1604 & 1,8022 & 28,6966 & 30,3896 & 2,4792 & 3,0741 & 30,8696 & 31,2149 \\
\hline Agregado** & 0,4283 & 0,6144 & 28,2397 & 28,7569 & 1,9877 & 2,4773 & 30,9678 & 30,9891 \\
\hline
\end{tabular}

Fonte: Elaboração própria.

Notas: * No resultado nominal, diferentemente do resultado primário, consideram-se as receitas e despesas com juros. ** O bem-estar agregado, referente ao agente típico da economia, é igual à soma das medidas de bem-estar individuais ponderados pelas respectivas frações da população, $\mathrm{L}_{p}$ e $\mathrm{L}_{q}$.

Em relação à PA1, nota-se que há perda de bem-estar considerável para as famílias do tipo $p$. Tais resultados tornam-se piores à medida que a vigência da política é expandida. Essa perda de bem-estar está intrinsecamente relacionada à diminuição nas transferências do governo destinadas aos agentes mais pobres e à redução no fornecimento dos bens ofertados às famílias. Sobre gestão fiscal destaca-se que, se implementada por 10 anos, em ambos os cenários de produtividade, o governo permaneceria com resultados primários positivos. Porém, se implementada por 20 anos, o governo passaria a apresentar déficits primários.

Apesar de estimular os investimentos do governo, em um cenário de estagnação da produtividade, a PA2 não logrará êxito na promoção de ganhos de bem-estar para todos os agentes da economia. Com aumento de produtividade, por outro lado, os ganhos gerais obtidos para todos os agentes são perceptíveis. Dessa forma, considerando o cenário g11, a PA2 
produziria ganhos de bem-estar mais próximos daqueles obtidos na ausência da EC 95/2016. Em termos macroeconômicos, o crescimento econômico no longo prazo torna visível a superação de gargalos.

\subsubsection{Políticas alternativas à Emenda Constitucional 95/2016}

Esta subseção testa duas alterativas de variáveis de ajuste da restrição orçamentária durante a vigência da EC 95/2016, de forma a verificar se, diante de um cenário de estagnação da produtividade, o ambiente econômico para as famílias mais pobres tornar-se-ia mais favorável na presença de uma reforma fiscal onde há congelamento dos gastos. Essas alternativas são a PA3, na qual a razão dívida/PIB $\left(B_{t}\right)$ é a variável de ajuste, e a PA4, na qual o investimento do governo $\left(I_{g t}\right)$ acomoda a restrição orçamentária. Em ambos os casos, as transferências para as famílias tipo $q\left(T R_{g t}\right)$ ajustam a restrição após a vigência e $\alpha_{p}$ retorna ao valor anterior à política. A Tabela 9 mostra os resultados para ambas as políticas.

Após a vigência da PA3, o retorno das transferências ao nível anterior à implementação da política ainda é insuficiente para trazer ganhos positivos de bem-estar para essas famílias. Ao ampliar o prazo de vigência da política em questão as perdas dos agentes mais pobres aumentam. Em contrapartida, os agentes do tipo $q$ desfrutam ganhos de bem-estar.

Tabela 9 Políticas alternativas (3 e 4) à EC 95/2016 (10 e 20 anos) sem ganhos de produtividade

\begin{tabular}{|c|c|c|c|c|}
\hline \multirow{2}{*}{ Variáveis } & \multicolumn{2}{|c|}{ Política Alternativa 3 (g00) } & \multicolumn{2}{|c|}{ Política Alternativa 4 (g00) } \\
\hline & 10 anos & 20 anos & 10 anos & 20 anos \\
\hline Resultado primário/PIB & 0,0092 & $-0,0153$ & 0,0154 & 0,0141 \\
\hline Resultado nominal/PIB* & $-0,0015$ & 0,0025 & $-0,0025$ & $-0,0023$ \\
\hline Produto & 0,9816 & 0,9641 & 1,0924 & 1,1867 \\
\hline Agentes p (xp) & $-2,9334$ & $-4,9632$ & 0,5959 & 0,9418 \\
\hline Agentes q (xq) & 0,9467 & 1,5127 & 2,4004 & 2,9622 \\
\hline Bem-estar agregado** & 0,2976 & 0,4295 & 2,0986 & 2,6242 \\
\hline
\end{tabular}

Fonte: Elaboração própria.

Notas: * No resultado nominal, diferentemente do resultado primário, consideram-se as receitas e despesas com juros. ${ }^{* *}$ O bem-estar agregado, referente ao agente típico da economia, é igual à soma das medidas de bem-estar individuais ponderados pelas respectivas frações da população, $\mathrm{L}_{p}$ e $\mathrm{L}_{q}$. 
Com relação à PA4, observou-se crescimento no nível dos investimentos públicos superior ao nível observado antes da política. Nota-se que as famílias mais pobres obterão variações positivas mesmo diante da ausência de crescimento de produtividade. Em suma, com a PA4 os gargalos redistributivos são reduzidos, principalmente pelo fato de que os investimentos públicos atuarão como indutores do crescimento da economia.

\subsubsection{Políticas alternativas à Emenda Constitucional 95/2016 com recompensas}

Como observado, as famílias mais pobres serão afetadas negativamente com a EC 95/2016 diante do cenário de estagnação da produtividade, exceto ao se permitir que o investimento público aumente. Na tentativa de eliminar possíveis distorções geradas pela implementação da EC 95/2016, esta seção analisa políticas alternativas de garantia de variação de bem- estar positiva mínima, PA5 e PA6, conforme descritas no Quadro 2.

Em cenário no qual o investimento mantém-se constante como variável da política (PA5), observou-se a possibilidade de as famílias do tipo $p$ obterem ganhos de bem-estar mínimos com o acréscimo de, aproximadamente, $39 \%$ na relação transferências para o agente $p$ no PIB em relação à situação sem a EC 95/2016, caso a vigência seja de 10 anos. Expandindo-se o prazo de vigência para 20 anos as famílias mais pobres obteriam ganhos de bem-estar mínimos somente se o valor de suas transferências no PIB se elevasse para, aproximadamente, o dobro do valor anterior à EC 95/2016.

Por outro lado, sob a vigência da PA6 a obtenção de um ganho mínimo de bem-estar positivo seria possível, inclusive, com uma redução das transferências para as famílias mais pobres a uma proporção de $93 \%$ para o caso de vigência de 10 anos e para uma proporção de $84 \%$ para o caso de 20 anos. Isso se deve ao fato de que a PA6, assim como a PA4, contorna os gargalos da economia através do aumento do investimento. Tal efeito reflete-se positivamente sobre os aspectos fiscais e macroeconômicos. Fato que melhora o ambiente fiscal facilitando, assim, uma gestão fiscal equilibrada. Os resultados estão descritos na Tabela 10. 
Tabela 10 Políticas de garantia de variação de bem-estar mínima alternativas à EC 95/2016 (10 e 20 anos) na ausência de ganhos de produtividade

\begin{tabular}{|c|c|c|c|c|}
\hline \multirow{2}{*}{ Variáveis } & \multicolumn{2}{|c|}{ Política Alternativa $5(g 00)$} & \multicolumn{2}{|c|}{ Política Alternativa $6(\mathrm{~g} 00)$} \\
\hline & 10 anos $^{1}$ & 20 anos $^{2}$ & 10 anos $^{3}$ & 20 anos $^{4}$ \\
\hline Resultado primário/PIB & 0,0091 & $-0,0155$ & 0,0154 & 0,0141 \\
\hline Resultado nominal/PIB* & $-0,0015$ & 0,0026 & $-0,0025$ & $-0,0023$ \\
\hline Produto & 0,9817 & 0,9643 & 1,0922 & 1,1864 \\
\hline Agentes p (xp) & 0,0378 & 0,0439 & 0,0322 & 0,05090 \\
\hline Agentes q (xq) & 0,7170 & 1,1232 & 2,4423 & 3,0318 \\
\hline Bem-estar agregado** & 0,6034 & 0,9427 & 2,0392 & 2,5332 \\
\hline
\end{tabular}

Fonte: Elaboração própria.

Notas: * No resultado nominal, diferentemente do resultado primário, consideram-se as receitas e despesas com juros. ${ }^{* *} O$ bem-estar agregado, referente ao agente típico da economia, é igual à soma das medidas de bem-estar individuais ponderados pelas respectivas frações da população, $L_{p} e L_{q}$.

Os resultados descritos ao longo desta seção evidenciam a necessidade de se considerar possíveis efeitos negativos de políticas fiscais sobre os próprios aspectos fiscais do governo, sobre os agregados macroeconômicos e sobre o bem-estar das famílias, sobretudo daquelas mais pobres. Como visto, uma política fiscal de contenção de gastos, tal como realizado pela EC 95/2016, pode implicar reduções dos níveis de bem-estar dos indivíduos mais pobres, sobretudo diante de um cenário de estagnação da produtividade da economia.

\section{Considerações finais}

Muito embora a reforma fiscal representada pela EC 95/2016 possa ajudar a gestão fiscal via redução da relação dívida/PIB, congelar os gastos do governo de forma arbitrária e sem uma análise acurada das consequências pode gerar resultados distorcidos severos. Tais consequências, observadas tanto pelas famílias que mais dependem da oferta de serviços públicos (famílias pobres) quanto pelos agregados macroeconômicos, podem implicar efeitos deletérios a todos os agentes dessa economia.

Por outro lado, a possibilidade de flexibilização dos investimentos e a respectiva compensação aos agentes mais prejudicados com a reforma levariam a um ambiente favorável ao crescimento econômico, mesmo dian- 
te de cenários de estagnação da produtividade da economia. Essa política, indiretamente por meio do aumento da arrecadação, geraria um ambiente favorável também para o desenvolvimento de uma gestão fiscal equilibrada.

Observou-se, portanto, que os resultados obtidos via implementação das políticas PA4, PA5 e PA6 gerariam ganhos para todos os agentes modelados nessa economia e não apenas atenderiam aos objetivos sob os quais se fundamentou a implementação da EC 95/2016 como também trariam outros benefícios positivos à gestão fiscal. Junte-se a isso o fato de essas políticas serem tipicamente factíveis. Assim, espera-se que este trabalho contribua para o debate político e econômico nacional posto na atualidade e possa auxiliar na orientação dos policymakers e lawgivers em termos de políticas públicas fundamentadas nesse arcabouço.

Uma vez que a EC 95/2016 já se encontra implementada e com remodelagem permitida prevista apenas para 2026, os resultados apresentados podem, pelo menos no curto prazo, orientar a criação de mecanismos auxiliares que visem minimizar os efeitos negativos supracitados. Tais resultados podem ainda auxiliar na avaliação de possíveis adaptações da EC 95/2016, quando permitida, aos moldes de alguma das políticas apresentadas neste trabalho.

\section{Referências}

ABREU, T. F. R.; LIMA, E. C. R. A Eficácia da Política Fiscal no Brasil: Uma Abordagem SVAR identificado com Restrições de Sinais e de Zeros. In: ENCONTRO NACIONAL DE ECONOMIA. 46., 2018, Rio de Janeiro.

ANDERSON, D.; HUNT, B.; SNUDDEN, S. Fiscal consolidation in the euro area: How much pain can structural reforms ease? Journal of Policy Modeling, Elsevier, v. 36, n. 5, p. 785-799, 2014.

ARROW, K; KURZ, M. Public Investment, the Rate of Return and Optimal Fiscal Policy. Baltimore, Md: Johns Hopkins Press, 1970.

BALL, L. M.; FURCERI, D.; LEIGH, D.; LOUNGANI, P. The Distributional Effects of Fiscal Consolidation, IMF Working Papers 13/151, International Monetary Fund. 2013.

BARRO, R. Government Spending in a Simple Model of Endogenous Growth. Journal of Political Economy, v. 98, p. 103-25, Oct. 1990.

BARRO, R; SALA-I-MARTIN, X. Public Finance in Models of Economic Growth. Review of Economic Studies, v. 59, p. 645-662, 1992.

BARRO, R; SALA-I-MARTIN, X. Economic Growth. 2. ed. Cambridge; Massachusetts; London; England: The MIT Press, 2004. 
BARROS, R. P.; FOGUEL, M. N.; ULYSSEA, G. Desigualdade de renda no Brasil: uma análise da queda recente. Brasília: IPEA, 2007.

BAXTER, M. KING, R. G. Fiscal Policy in General Equilibrium. The American Economic Review, v. 83, n. 3, p. 315-334, 1993.

BEZERRA, A. R.; PEREIRA, R. A. C.; CAMPOS, F. A. O.; CALLADO, M. C. Efeitos de crescimento e bem-estar da recomposição dos investimentos públicos no Brasil. Pesquisa e Planejamento Econômico, Rio de Janeiro, v. 44, p. 579-607, 2014.

BEZERRA, A. R.; PEREIRA, R. A. C.; FERREIRA, M. D.; CALLADO, M. C. A macroeconomic analysis of the welfare effects of the privatization of state enterprises in Brazil. The Empirical Economics Letters, v. 17, n. 9, p. 1.121-1.128, Sept. 2018.

BOVA, E.; KINDA, T.; WOO, J. Austerity and inequality: The size and composition of fiscal adjustment matter. Vox CEPR Policy Portal, 2018.

BRASIL. SECRETARIA DO TESOURO NACIONAL. Gasto Social do Governo Central 2002 a 2015, 2016a.

BRASIL. Câmara dos Deputados. Emenda Constitucional No 95, de 15 de Dezembro de 2016. Altera o Ato das Disposições Constitucionais Transitórias, para instituir o Novo Regime Fiscal, e dá outras providências. 2016b.

CAMPOS, F. A. O.; PEREIRA, R. A. C. Corrupção e ineficiência no Brasil: uma análise de equilíbrio geral. Estudos Econômicos, v. 46, p. 373-408, abr./jun. 2016.

CAMURI, P. A. G; JAYME JR., F.; HERMETO, A. M. Consolidação fiscal em economias desenvolvidas e emergentes. Nova Economia, v. 25 (spe), p. 835-861. 2015.

CARDOSO, G.; CARDOSO, D. F.; DOMINGUES, E. P. Austeridade fiscal no Brasil: Impactos na renda das famílias e na atividade econômica. In: SEMINÁRIO DE DIAMANTINA. 18., 2019, Diamantina. Anais...

CHARI, V. V.; CHRISTIANO, L. J.; KEHOE, P. J. Optimal Fiscal Policy in a Business Cycle Model. Journal of Political Economy, University of Chicago Press, 102, p. 617-652. 1994.

CHARI, V. V.; CHRISTIANO, L. J., KEHOE, P. J. Policy Analysis in Business Cycle Models. Frontiers of Business Cycles Research, edited by T. F. Cooley, 12:357-391, Princeton, NY: Princeton University Press, 1995.

CHATTERJEE, S.; GHOSH, S. The dual nature of public goods and congestion: the role of fiscal policy revisited. Canadian Journal of Economics, v. 44, issue 4, p. 1.471-1.496, 2011.

COOLEY, T. F.; PRESCOTT, E. C. Economic growth and business cycles. In: COOLEY, T. F. (Ed.). Frontiers of business cycle research. Princeton: Princeton University Press, 1995.

EICHER, T.; TURNOVSKY, S. J. Scale, Congestion and Growth. Economics, New Series, v. 67, n. 267 , p. $325-346,2000$.

FERREIRA, P. C. Essays on Public Expenditure and Economic Growth. Unpublished Ph.D. Dissertation - University of Pennsylvania, Philadelphia, United States, 1993.

FERREIRA, P. C.; NASCIMENTO, L. G. Welfare and growth effects of alternative fiscal rules for infrastructure investment in Brazil. Ensaios Econômicos, EPGE 604, Fundação Getulio Vargas, 2006.

GERARDO, J. Receitas Atípicas e Restos a Pagar: implicações sobre o Resultado Primário do 
Governo Central. XV Prêmio Tesouro Nacional: Política fiscal e sustentabilidade do crescimento, 2010.

GIAMBIAGI, F. 18 anos de política fiscal no Brasil: 1991/2008. Economia Aplicada, São Paulo, v. 12, n. 4, p. 535-580, 2008.

GIAVAZZI, F.; PAGANO, M. Can severe fiscal contractions be expansionary? Tales of two small European countries. NBER Macroeconomics Annual, MIT Press, v. 5, p. 75-111, 1990.

GOMES, J. W. F.; BEZERRA, A. R.; PEREIRA, R. A. C. Efeitos macroeconômicos e redistributivos de políticas fiscais no Brasil. In: ENCONTRO NACIONAL DE ECONOMIA. 43., 2015, Florianópolis, SC. Anais...

GOMES, J. W. F.; PEREIRA, R. A. C.; BEZERRA, A. R. Efeitos distributivos do aumento nos investimentos públicos em infraestrutura no Brasil. Pesquisa e Planejamento Econômico, v. 49, n. 2, 2019.

HOLLAND, M. Fiscal crisis in Brazil: Causes and remedy. Brazilian Journal of Political Economy, v. 39, n. 1, p. 88-107, 2019.

LANSING, K. J. Optimal fiscal policy in a business cycle model with public capital. The Canadian Journal of Economics, v. 31, n. 2, p. 337-364, May 1998.

LOUREIRO, A. O. F.; SULIANO, D. C.; DE OLIVEIRA, J. L. Uma Análise da pobreza no Ceará com base em diferentes linhas de mensuração. Fortaleza, IPECE, 2010. Texto para discussão.

LUCAS, R. E. On the mechanics of economic development. Journal of Monetary Economics. Chicago, v. 22, p. 3-42, 1988.

LUCIO, F. G. C. Ineficiência no setor público: uma análise dos efeitos macroeconômicos e de bem-estar. Dissertação (Mestrado) - Universidade Federal do Ceará, Fortaleza, 2017.

PEREIRA, R. A. C.; FERREIRA, P. C. Efeitos de crescimento e bem-estar da Lei de Parceria Público-Privada no Brasil. Revista Brasileira de Economia, v. 62, n. 2, p. 207-219, 2008.

PEREIRA, R. A. C.; FERREIRA, P. C. Avaliação dos impactos macroeconômicos e de bem-estar da reforma tributária no Brasil. Revista Brasileira de Economia, v. 64, p. 191-208, 2010.

PEREIRA, R. A. C.; FERREIRA, P. C. Impactos macroeconômicos da cobrança pelo uso da infraestrutura pública no Brasil. Pesquisa e Planejamento Econômico, v. 41, n. 2, p. 183-212, 2011.

PEREIRA, R. A. C.; FERREIRA, P. C. Privatização: uma análise de bem-estar. Estudos Econômicos, São Paulo, v. 48, n. 3, p. 391-422, set. 2018.

PINTEA, M., TURNOVSKY, S. J. Congestion and Fiscal Policy in a Two-Sector Economy with Public Capital: A Quantitative Assessment. Computational Economics, v. 28, p. $177-$ 209, Springer, 2006.

ROMER, P. M. Increasing returns and long-run growth. Journal of Political Economy, Chicago v. 94, p. 1.002-1.037, 1986.

SAMUELSON, P. A. The pure theory of public expenditure. Review of Economics and Statistics, v. 36, p. 387-389, 1954.

SANTANA, P. J; CAVALCANTI, T. V. V.; PAES, N. L. Impactos de longo prazo de reformas fiscais sobre a economia brasileira. Revista Brasileira de Economia, v. 66, p. 247-269, 2012.

SOUZA JÚNIOR, J. R. C.; SANTOS, F. Simulações da trajetória da dívida bruta do governo 
geral (2017 a 2037).- Brasília: Rio de Janeiro: IPEA, 2017. Texto para discussão.

SCHNEIDER, M. P.; KINSELLA, S.; GODIN, A. Changes in the profile of inequality across europeu since 2005: Austerity and redistribution. European Journal of Economics and Economic Policies: Intervention, Edward Elgar Publishing, v. 13, n. 3, p. 354-374, 2016.

TURNOVSKY, S. J. Fiscal Policy, Adjustment Costs, and Endogenous Growth. Oxford Economic Papers, v. 48, p. 361-381, 1996.

UZAWA, H. Neutral Inventions and the Stability of Growth Equilibrium. Review of Economic Studies, v. 28, n. 2, p. 117-124, Feb., 1961.

\section{Sobre os autores}

José Weligton Félix Gomes - weligtongomes@gmail.com

Curso de Pós-Graduação em Economia - CAEN, Universidade Federal do Ceará, Fortaleza, CE, Brasil.

ORCID: https://orcid.org/0000-0001-5983-9204.

Ricardo A. de Castro Pereira-rpereira@caen.ufc.br

Curso de Pós-Graduação em Economia - CAEN, Universidade Federal do Ceará, Fortaleza, CE, Brasil.

ORCID: https://orcid.org/0000-0003-0210-2142.

Arley Rodrigues Bezerra-aleyrb@hotmail.com

Universidade Federal Rural de Pernambuco, Campus Serra Talhada, PE, Brasil.

ORCID: https://orcid.org/0000-0001-6055-891X.

Francisco Germano Carvalho Lúcio - germanocarvalho@caen.ufc.br

Doutorando do Curso de Pós-Graduação em Economia (CAEN), Universidade Federal do Ceará, Fortaleza, CE, Brasil. ORCID: https://orcid.org/0000-0001-9153-4849.

Francisco Assuero Monteiro Saraiva - assueroms@hotmail.com

Doutorando do Curso de Pós-Graduação em Economia (CAEN), Universidade Federal do Ceará, Fortaleza, CE, Brasil.

ORCID: https://orcid.org/0000-0003-0755-2011.

Os autores agradecem aos pareceristas anônimos as sugestões e as críticas. Agradecem, ainda, o financiamento da Coordenação de Aperfeiçoamento de Pessoal de Nível Superior (CAPES) e do Conselho Nacional de Desenvolvimento Científico e Tecnológico (CNPq) e o apoio da Pró-Reitoria de Pesquisa e Pós-Graduação (PRPPG) da Universidade Federal do Ceará (UFC). Ricardo A. de Castro Pereira, adicionalmente, agradece o financiamento do Programa de Educação Tutorial (PET) da Secretaria de Educação Superior (Sesu) do Ministério da Educação (MEC) e o financiamento dos Institutos Nacionais de Ciência e Tecnologia (INCT) do CNPq.

\section{Sobre 0 artigo}

Recebido em 11 de fevereiro de 2019. Aprovado em 12 de fevereiro de 2020. 